\title{
ДУХОВНО-НРАВСТВЕННЫЕ ИСКАНИЯ
}

\author{
С.С. Хоружий
}

\section{ИСИХАЗМ И ФЕНОМЕНОЛОГИЯ}

\begin{abstract}
Аннотация. Поле философских проблем, возникающих при изучении мистико-аскетической практики исихазма, структурируется в три основных топоса: "Исихазм и феноменология", "Исихазм и энергия", "Исихазм и размыкание человека». Проделан анализ первого из этих топосов, где собраны проблемы методологии, эпистемологии и эвристики духовного и философского опыта. Компаративное рассмотрение исихастского и феноменологического (интенционального) опыта обнаруживает между ними тесную близость и существенные структурные параллели: тройственное строение пути духовного восхождения в исихазме находится в соответствии с тремя стадиями феноменологического акта узрения интенционального предмета (феноменологическая редукция - интенциональное всматривание - ноэзис). Исихастская установка трезвения (перліs) характеризуется как специфический модус сознания, во всех основных чертах совпадающий с интенциональным сознанием.
\end{abstract}

Ключевые слова: философия, феноменология, исихазм, аскетика, анахореза, интенциональность, феноменологическая редукция, ноэзис, трезвение, внимание.

Abstract. The field of philosophical problems generated by the study of the hesychast mystico-ascetical practice is structured into three principal domains: Hesychasm and Phenomenology, Hesychasm and Energy, Hesychasm and the Anthropological Unlocking. The first of these domains is analyzed, in which problems of methodology, epistemology and heuristics of spiritual and philosophical experience are collected. Comparative study of hesychast and phenomenological (intentional) experience demonstrates that these two kinds of experience possess close resemblance and structural parallels. Namely, the triadic structure of the way of spiritual ascension in hesychasm corresponds to three stages of the phenomenological act of the grasping of the intentional object (phenomenological reduction - intentional grasping - noesis). The hesychast principle of soberness (nepsis) is characterized as a specific modus of consciousness, which coincides with intentional consciousness in all principal features.

Key words: phenomenological reduction, intentionality, anachoresis, ascesis, hesychasm, phenomenology, philosophy, noesis, soberness, attention.

«Анализ мистического сознания представляет для философии одну из интереснейших проблем».

(Г. Шпет [1, с. 48])

Размышления над логикою развития русской мысли давно уже привели меня к выводу о том, что это развитие, оборванное и деформированное катаклизмами отечественной истории, с необходимостью подводило к задаче пристального, всестороннего изучения квинтэссенциального православного опыта - опыта исихастской практики. Этот вывод стал для меня руководством к действию. Вся многодисциплинарная проблематика изучения антропологии исихазма, равно как и других духовных практик, прежде систематически не разбиралась в науке, и мои исследования этой антропологии, занявшие немало лет, оказались, по известному выражению, - пускай хотя бы и в скромной мере - путешествием за открытиями. Обнаружилось немало нового, интересного, а порой и принципиально важного. Один из наиболее крупных выводов был таков, что опыт исихазма и типологически родственных ему практик других мировых религий должен рассматриваться как некоторый самостоятельный и ранее не описанный

Работа выполнена при поддержке РГНФ, проект № 14-03-00109 «Антроподиагностика современной социальной реальности на базе синергийной антропологии» (Anthropological Diagnostics of Modern Social Reality on the Basis of Synergic Anthropology). 


\section{Философия и культура 5(101) • 2016}

род антропологического опыта, который характеризуется целым рядом специфических отличительных черт. Из них главными и определяющими являются две: онтологическая природа и эпистемологическая прозрачность. Обе эти формулы несут весьма глубокое содержание, нуждаясь в пояснении и раскрытии.

Эпистемологическая прозрачность означает, что опыт духовной практики есть опыт проработанный и отрефлектированный, с отчётливой, прозрачной организацией. Всякая духовная практика обладает строгим методом; в случае исихазма, сама практика даже прямо и называлась «Метод» в сообществе её участников. Больше того, как я выяснил, здесь - метод особого рода, представляющий собой полноценный органон в изначальном Аристотелевом смысле понятия: полный практико-теоретический канон некоторого вида полного опыта. (В свою очередь, полнота опыта означает, что в данном опыте полностью выявляется определённая природа, physis.) В состав этого органона входят все правила организации, проверки и истолкования опыта. Он называется также «внутренний органон», в отличие от другого органона, «внешнего», который представляет собой полное описание структур исихастского опыта с позиций уже не самих исихастов, а современного научного сознания. Создание внутреннего органона, его непрерывное и строго тождественное воспроизводство, его трансляция во времени и пространстве - главная задача духовной практики как таковой. Его наличие, обеспечивающее эпистемологическую прозрачность опыта, позволяет заключить, что духовные практики могут рассматриваться как своеобразные школы - или, если угодно, кузницы, мастерские, фабрики... - чистого антропологического опыта.

Здесь можно вспомнить, что современные направления культурной антропологии строят концепцию человека, как правило, начиная с дескрипции опыта некоторой примитивной культуры (племён Амазонии, Полинезии и т.п.) - опыта, который относительно несложен, прозрачен, а потому может быть концептуализован, а затем и обобщён на общеантропологический уровень. Но в силу своей эпистемологической прозрачности, опыт духовных практик также может быть концептуализован и обобщён! И тем самым, этот опыт может составить успешную конкуренцию опыту примитивных культур в качестве исходного плацдарма для построения неклассической концепции человека. Так обращение к исихастскому опыту приводит к открытию альтернативы мейнстриму современной антропологической мысли. При этом опыт ду- ховных практик является более высокоразвитым, антропологически полномерным, чем опыт примитивного сознания, и за счёт этого данная альтернатива имеет определённые преимущества.

Что же до онтологической природы духовной практики, то она означает, что эта практика ставит целью актуальное онтологическое изменение: изменение способа бытия человека, фундаментальных предикатов человеческого существования. Иными словами, её цель, состояние, которого она стремится достичь, не принадлежит области наличного или эмпирического бытия и лежит за пределами горизонта сознания и опыта человека. Вследствие этого оба свойства оказываются взаимосвязаны. Цели духовной практики просто не существует в поле опыта человека, в эмпирическом бытии (отчего её часто и не называют целью, более адекватен греческий термин «телос», цель-смысл), и потому адепт практики не имеет возможности из собственного опыта определить путь и способ продвижения к ней; для её успешного прохождения он должен получить полную путевую инструкцию. Именно для этого и создаётся органон практики: его назначение - служить полной инструкцией для участников практики. Понятно, что именно необходимость полноты инструкции имплицирует необходимость для практики не просто метода, но органона: опыт должен быть полным опытом, чтобы практика могла нести актуальное онтологическое содержание. Таким образом, онтологическая природа духовной практики порождает необходимость её органона и её эпистемологической прозрачности.

Уже из этой первой характеристики исихастского опыта ясно, что в его изучении открывается существенная философская проблематика. Au vol d'oiseau в большой теме «Исихазм и философия» можно усмотреть три основных проблемных поля, топоса:

1) Исихазм и феноменология. В этот топос сводится большинство философских вопросов, связанных с исихастским органоном, с методологией, эпистемологией и герменевтикой исихастского опыта. Отчего это так, в чём связь этих вопросов с феноменологией? Априори это не ясно, но на поверку связь довольно прямая, и содержание данного топоса оказывается весьма богатым.

2) Энергия в исихазме. В эпоху Исихастского возрождения в Византии в XIII-XIV вв. опыт высших ступеней исихастской практики вызвал необычайные дискуссии, длительные и углублённые. В этих дискуссиях оформилась новая область православного богословия - богословие Божественных энергий, созданное, главным образом, исихастским учителем св. Григорием Паламой и имеющее исихастскую практику основой своей опытной базы. В 
рамках этого богословия происходит изучение концепции энергии, сочетающее богословскую и философскую проблематику и подход. В наше время внимание к философской проблеме энергии очень усилилось, благодаря, прежде всего, Хайдеггеру, а в России - Бибихину. Хотя Хайдеггер не обращается к исихастскому опыту, но в целом православно-паламитская трактовка энергии и её изучение остаётся существенною частью современной проблематики энергии.

3) Исихазм и концепция размыкания человека. Анализ исихастской практики выявляет, что в осуществляемом в ней восхождении-трансцендировании человека ключевая роль принадлежит синергии - встрече и согласному соустроению-соработничеству энергий человеческих и Божественных. Синергия служит необходимым условием и решающей предпосылкой того, что в практике, в восхождении по «Райской Лествице» исихазма формируется конституция человека. В антропологическом же аспекте синергия есть событие, в котором человек делает себя открытым, разомкнутым для встречи с энергиями, принадлежащими иному способу бытия, имеющими иной онтологический статус; иными словами, синергия - это не что иное как онтологическое размыкание человека. Данное наблюдение становится отправным пунктом для построения синергийной антропологии - общей концепции человека, трактующей его как сущее, которое конституируется посредством размыкания себя в предельном опыте. Наряду с онтологическим размыканием, здесь обнаруживаются ещё два вида конститутивного размыкания человека, онтическое и виртуальное; и синергийная антропология (иногда также называемая «антропологией размыкания») развёртывается как три относительно независимых комплекса исследований, где изучаются эти три базовых вида антропологического размыкания. Из них, исследование онтологического размыкания остаётся тесно связанным с исихастской практикой - и, стало быть, тоже входит в тему «Исихазм и философия».

Помимо этих трёх крупных топосов, можно, разумеется, найти целый ряд более частных и конкретных соприкосновений философии с феноменом исихазма. Наиболее значительные из них обнаруживаются в мысли Хайдеггера и Фуко. У Хайдеггера и в раннем, и в позднем творчестве немало перекличек с христианской духовной практикой, а в позднем периоде - также и с восточными духовными практиками (основные из них были мною рассмотрены [см.: 2, с. 426-473, 487-491]). Это - переклички в достаточно важных темах, таких как конституирование человека в размыкании себя и концепция «экстатического выступания присутствия (Dasein) в просвет бытия». Что же до Фуко, то он и непосредственно обсуждает феномен восточно-христианской аскезы, отводя ему заметное место в своей «христианской модели практик себя». Критический анализ этой трактовки был дан в моей указанной книге.

После общего обозрения темы, мы кратко рассмотрим первый из её основных топосов. Начальный вопрос уже задан выше: какие же нити связывают исихастский органон с философской феноменологией? Ответ не столь труден. Научная реконструкция органона исихастского опыта предполагает его концептуализацию, которая должна быть интегрирована в философский дискурс об опыте и сопоставлена, сообразована с базовыми философскими концепциями опыта. Ясно, что для такого сопоставления крайне неадекватна старая позитивистская парадигма опытного познания, выражающая опыт естественных наук и отвечающая внешней, дистанцированной регистрации событий. Исихастский опыт - опыт жизни сознания, внутренней жизни, и очевидно, что исихастский органон неизмеримо далёк от когнитивных парадигм естественнонаучного знания. Напротив, с трактовкой опыта в феноменологии Гуссерля связи и сближения устанавливаются почти немедленно.

Прежде всего, феноменология обращалась именно к опыту сознания, описывая структуры и парадигмы этого опыта и развивая способ дескрипции реальности изнутри мира сознания, в его перспективе - иными словами, описывая мир как опыт. Тем самым, в отличие от позитивистской когнитивной парадигмы, в её рамках изначально имелись известные предпосылки к тому, чтобы осуществлять дескрипцию внутреннего опыта и в частности, опыта исихазма. Помимо того, феноменология мыслилась как глобальный проект, который должен описывать и анализировать феномены человеческого опыта, включая в свою орбиту все виды этого опыта, всё его сущее многообразие. В силу этой глобальной и универсальной природы проекта, он должен был включить в свою сферу и религиозный опыт. Сам Гуссерль, однако, относился к такому заданию осторожно и амбивалентно, по целому ряду причин: например, он был очень чуток к весьма реальной опасности поверхностных сближений и даже сливаний, которые могли делаться и делались между «переживанием» (Erlebnis) как концептом феноменологии и как реалией религиозной сферы; помимо того, религиозный опыт - крайне гетерогенный, смешанный 


\section{Философия и культура 5(101) • 2016}

опыт, в котором элемент собственно религиозный, т.е. актуализующий отношение человека к онтологически Иному, сращен с различными сопутствующими, смежными видами опыта - опытом социальным, эмоциональным и др. И всё же задание не отвергалось. Так, Густав Шпет в 1913 г., когда он был безусловным приверженцем феноменологии и одним из близких последователей Гуссерля, писал своему учителю: «Феноменология является основой ... любого практического и аксиологического знания ... основой «жизни» и «философской жизни» в целом... Разве в рамках феноменологической установки мы не собираемся описывать и анализировать также и переживания (Erlebnisse), подобные переживаниям св. Терезы или Я. Бёме, или разговоры св. Фомы с Богом?» [3, с. 125]. Итак, исихастский опыт хотя бы в принципе допускает феноменологическую трактовку, входит в орбиту феноменологической дескрипции.

Однако и более того. В отличие от религиозного опыта в целом, опыт, культивируемый в духовных практиках, не смешан, а чист, будучи специально и тщательно очищаем от всех инородных примесей. Он эпистемологически прозрачен и наделён органоном. Исихастский органон и метод феноменологической дескрипции обнаруживают далеко идущую общность, которая начинается с самых общих установок отношения к опыту. Феноменология добивается эпистемологической прозрачности опыта ещё более усиленно и категорично, нежели исихазм. Она также представляет собою строгий метод, и более того, данный метод также представляет собою полноценный органон. Это органон интенционального опыта, включающий в себя известные основные стадии: феноменологическая редукция - интенциональное всматривание - ноэзис. И соответственно, возникает содержательная задача систематического сопоставления исихастского и феноменологического органонов.

Сопоставление с феноменологией стоит проводить для цельного феномена исихазма, с учётом и исторического измерения. Поэтому начнём с замечания о связи практики и традиции.

Со всякой духовной практикой связано сообщество её участников, которое существует в обществе и в истории, обеспечивает трансляцию искусства практики во времени и пространстве и носит название духовной традиции. Практика индивидуальна, однако может полноценно осуществляться лишь в сообществе, в лоне традиции. Вследствие этого, духовная практика и духовная традиция образуют двуединство, диаду, которая обладает аналогией с биологической системой «особь - популяция». Данная аналогия проявляет- ся, в частности, в том, что в существовании диады прослеживается определённое подобие биогенетического закона, повторения филогенеза в онтогенезе. Так, в случае исихазма индивидуальная практика есть ступенчатый процесс, восхождение по «Райской Лествице», ведущей от обращения и покаяния к обожению (уже не принадлежащему здешнему бытию) и в своей крупной структуре делящейся на три блока:

- «Блок отрыва», в котором адепт совершает радикальный исход из мира, разрыв со всеми практиками, правилами, обычаями мирской жизни;

- «Блок онтодвижителя», в котором адептом создаётся особая конфигурация своих энергий и особая практика «соединения молитвы и внимания», дающая необычайную силу собранного молитвенного устремления и позволяющая достичь онтологического размыкания человека, его открытости для Божественной энергии;

- «Блок телоса», в котором Божественная энергия начинает совершать преображающее действие в человеке и появляются первые начатки фундаментального переустроения человеческого существа. В первую очередь, это трансформация перцептивной сферы, формирование новых перцепций, так называемых «умных чувств».

В свою очередь, историческое существование исихастской традиции в эпоху её формирования, создания исихастского органона, также отчётливо расчленяется на три больших периода:

- $\quad$ исихазм начальный, или же «исихазм до исихазма»: раннее монашество Отцов-пустынников Коптского Египта и Палестины в IV-VI вв., породившее оппозицию «Империя - Пустыня»;

- «Синайский исихазм» VII-X вв.: в этот период подвижниками Синайских монастырей осуществляется оформление и осмысление исихастской практики как цельного духовно-антропологического процесса. Складываются основы «Умного делания» - школы непрестанного творения Иисусовой молитвы, стоящего на сцепке молитвы и внимания;

- Исихастское возрождение XIII-XIV вв.: в центре внимания традиции - опыт афонских исихастов, воспринимаемый ими как созерцание Фаворского Света (Света, что осиял учеников Христа в событии Преображения на Фаворе). После ожесточённых «Исихастских споров» и появления богословия Божественных энергий в трудах Паламы, позиция исихастов закрепляется в решениях Собора 1351 г., и формирование исихастского органона, в основном, достигает завершения. 
Из этих двух тройственных схем отчётливо выступает соответствие между ними, структурный параллелизм, являющийся подобием биогенетического закона. Первая, антропологическая триада - «исихастский онтогенез», вторая, историческая - «исихастский филогенез», и мы без труда видим, как в первой находят отражение, воспроизводятся этапы второй. Начальные ступени практики, «Блок отрыва», посвящены тем же задачам, которые разрешались «Исихазмом до исихазма», в подвижничестве Отцов-пустынников. Центральная часть практики, «Блок онтодвижителя», имеет те же главные задания, которые ставил перед собою и выполнял Синайский исихазм. Наконец, в заключительном «Блоке телоса» исихаст достигает тех высших ступеней опыта, которых традиция достигала и которые вбирала в себя, осмысливала на этапе Исихастского возрождения и Исихастских споров. Итак, процессы исторический и антропологический оказываются параллельны, соотносимы.

Представление исихазма диадой практика традиция, диадой из двух триад, оказывается удобным стартом для сопоставления с феноменологическим органоном. В своём крупном строении этот последний также представляется как триада: феноменологическая редукция - интенциональное всматривание - ноэзис, и как мы ниже покажем, возможно установить поэлементное соответствие между этой феноменологической триадой и обеими исихастскими триадами.

Притом, обнаруживаемое соответствие оказывается довольно тесным сближением. Как выяснится, исихастский опыт, будучи методичным и отрефлектированным, уже изначально и «в себе», в своей собственной, имманентной организации чрезвычайно близок к структуре феноменологического (интенционального) опыта, включая в себя стадии редукции, интенционального всматривания и, в некоторой обобщённой форме, ноэзиса - хотя, разумеется, все эти стадии описываются в аскетическом дискурсе, далёком от философского. Тем самым, в своей внутренней организации, «внутреннем органоне», исихастский опыт (и шире, опыт духовных практик) имманентно, хотя и имплицитно, феноменологичен. Уже и сам для себя, этот опыт представляет себя как феноменологический, интенциональный опыт; и это является ещё одним веским фактом, говорящим об универсальности феноменологической парадигмы, о том, что качество интенциональности неотъемлемо присуще работе сознания. Как констатировал Шпет, «интенциональность - существенный признак сознания» $[1$, с. 46$]$, и наш анализ исихастского сознания это подтверждает.
Исихазм до исихазма: Анахореза как редукция. С самого начала секуляризации, в европейской светской культуре одной из постоянных мишеней насмешек и враждебной иронии служило отшельническое монашество, аскеза отцов-пустынников. В них видели крайнее выражение, символ асоциальности и обскурантизма, воинствующий вызов идеалам знания и культуры. Современная рецепция аскетизма убедительно раскрыла, однако, что в раннем монашестве (которое первоначально возникло в египетском, коптском христианстве) уход в пустыню, анахоретство было эффективным, а то и прямо необходимым средством, с помощью которого созидались иное знание и иная культура. К этому мы добавим конкретный тезис: в построении опыта духовной практики, направленного к онтологической трансформации человека, уход в пустыню служит начальной ступенью, которая и по назначению, и по содержанию аналогична стадии феноменологической редукции в интенциональном опыте.

Редукция осуществляет конституцию новой когнитивной перспективы, в которой горизонт сознания ограничен миром субъектного опыта. Именно это же осуществляется и в уходе в пустыню. В обоих случаях, перед нами - радикальный жест (само) ограничения и, в этом смысле, аскетический акт; В пору становления феноменологии, предписываемую ею строгую дисциплину разума нередко называли аскетической, или аскезой разума (как позднее Фуко будет говорить о философии как аскезе). Цель этого акта ограничения (отсечения, взятия в скобки и т.п.) - убрать, исключить из поля зрения и восприятия всё лишнее, что мешает концентрации на главной, сугубо внутренней задаче. В феноменологии, редукция конституирует мир сознания как мир субъектного опыта, способный к дальнейшему препарированию, которое осуществляют следующие стадии интенционального акта. В духовной практике, уход в пустыню конституирует мир сознания как мир аскетического опыта, аскетической традиции, способный к дальнейшей трансформации, которая будет выстраиваться как лестница духовно-антропологического восхождения с помощью «внутреннего органона», предоставляемого традицией.

Разумеется, бегство из мира не ограничивается внешним уходом - непрерывно продолжаясь, оно интериоризуется, переходит из внешнего во внутренний мир. Суть этой интериоризации в том, что во внутреннем мире подвижника точно так же совершается самоограничение: в нём отсекается всё, что не входит в специфический мир аскетического опыта, который есть не что иное как Универсум Традиции. Традиция выступает тут как особый и притом краеугольный концепт: всевременная 


\section{Философия и культура 5(101) • 2016}

целокупность истинного испытанного опыта всех участников. Она выступает как замкнутый и полный мир, Универсум исихастского опыта и органона, и всякий опыт в качестве испытания должен пройти помещение в этот мир, в его перспективу, в итоге чего будет отсечено всё индивидуальнопсихологическое и случайное, всё, не отвечающее чистому содержанию духовного процесса.

Данное описание уже полностью соответствует феноменологической редукции, в некой определённой вариации. Феноменологический акт помещает опытное содержание в мир субъектного опыта, строит мир-как-опыт и в его перспективе очищает опыт, отсекая всё, не соответствующее структурам трансцендентальной субъективности. Оба подхода следуют в существенном по тому же пути. Аскетический Универсум Традиции и феноменологический мир-как-опыт выполняют ту же нетривиальную роль: они конструируют особое пространство опыта, в перспективе которого возникает особое видение реальности и строится особая антропологическая стратегия, стратегия самореализации человека. При этом излишне говорить, что они абсолютно не совпадают, ибо относятся к чрезвычайно различным горизонтам опыта. В качестве одного лишь отличия укажем, что Универсум Традиции оказывается синхронизированным миром общения всех участников, оказывается миром живым и диалогичным, чего отнюдь не предполагается для мира-как-опыта феноменологии.

Исихастская вариация редукции эксплицируется посредством специальных аскетических категорий, таких как apotage (отвержение, отрешённость), amerimnia (оставление забот), hesychia (уединённый покой) и др., а также с помощью особого жанра «апофтегм», кратких историй, научающих аскетическому «взятию в скобки». Типичные описания этой редукции в исихастской литературе ясно показывают её сущностное совпадение с феноменологической редукцией. Ср.: подвижник начинает путь аскезы, «прервав все связи с земным, сложив с себя всякое попечение, всего совлекшись, нагой...» (не есть ли сознание в редукции - «нагое сознание»?); «первое дело безмолвия - предварительное сложение с себя попечения о всех делах, и благовидных, и неразумных» $[4$, с. 28, 238] и т.д. и т.п. Ещё одна формула «исихастской редукции» - девиз, услышанный свыше, согласно одной из апофтегм, аввой Арсением, пустынником строжайшего жития: «убегай, скрывайся, храни молчание» (лат. fuge, late, tace). Эта формула стала, пожалуй, самой популярной из всех, получив удивительную жизнь в западной культуре: её делает своим девизом Люсьен де Рю- бампре, герой романов Бальзака, а затем, позаимствовав у Бальзака, - Джеймс Джойс.

Формирование описанной установки сознания, как во внешних, так и во внутренних её аспектах, можно относить к раннему, преимущественно, коптскому исихазму IV-VI вв.

Синайский исихазм: Трезвение как интенциональность. По выполнении редукции, феноменологическое сознание проводит непосредственно акт интенционального всматривания, в котором развёртывается в работе сама интенциональность как таковая. При этом, она развёртывается не как отдельное свойство сознания, но как определённый модус сознания, объединяющий в себе весь основной арсенал интенциональных концептов: Abzielen, Erfassen, Aufmerksamkeit, Achtsamkeit, u.s.w. В этом модусе осуществляется пристальная нацеленность на интенциональный предмет и устойчивое держание предмета в фокусе интенционального зрения. Исихастское же сознание после выполнения начальных стадий «аскетической редукции» также развёртывает специальный модус - модус трезвения, в котором осуществляется точно такая же активность (однако не с произвольным интенциональным предметом, а с весьма специальным: им служит целостный энергийный образ человеческого существа). Трезвение (nepsis) - установка бдительной собранности сознания, являющая собой полный аналог интенциональности и разделяющая все её ключевые свойства, начиная с преодоления в ней Аристотелевой оппозиции пассивности и активности (напомним, что данное свойство интенциональности утверждается Гуссерлем в поздней её трактовке, после «Логических исследований»; в частности, оно разбирается в 4-м из «Картезианских размышлений»). (Можно заметить, что понятие интенциональности имеет связи и с западной монашеской традицией. Ещё в Монастырском Уставе св. Бенедикта (VI в.), монаху вменяется установка intentio, концентрации внимания на читаемом тексте. Отсюда, в «Лестнице монахов» Гвиго Второго Картузианца (ХII в.), западном аналоге «Лестницы» Иоанна Синаита, intentio выступает как принадлежность первой ступени, lectio, лестнищы духовного восхождения, имеющей вид: Lectio - Meditatio - Oratio - Contemplatio. Haдо, однако, уточнить, что эта западная Лестница принадлежит, в терминах синергийной антропологии, не парадигме духовной практики, а родственной ей парадигме духовных упражнений. Вторая парадигма - существенно урезанная форма первой, не обладающая онтологическим измерением.) Это чисто исихастский концепт, который традиция 
создала и выдвинула в центр своего внутреннего органона в период Синайского исихазма VII-X вв., когда главными её очагами служили монастыри на горе Синай. Именно в нём исихазм достигает своего максимального сближения с феноменологией. Подобно интенциональности, трезвение выступает центром концептуального комплекса, описывающего - но теперь в аскетическом дискурсе! - особый модус сознания, в котором осуществляется событие интеллектуального узрения.

Главные элементы модуса трезвения суть: внимание (членимое на ряд видов: внимание ума, сердца, внимание к себе и др.), память (также членимая памятование о Боге, память смертная, память о грехах своих... (Подчеркнём, что все предметы памятования - внутри горизонта, определённого «аскетической редукцией», они суть прямые содержания аскетического опыта.)), самонаблюдение, различение (diacrisis), хранение или стража ума и отдельно - сердца, бодрствование, бдительность, «внутрь-пребывание» (особый род интроспекции, термин преп. Феофана Затворника), сердечное безмолвие (hesychia), чистота сердца. В этом многообразии можно выделить порождающее ядро из трёх элементов: трезвение - внимание (prosoche) стража (phylake), которым обеспечивается главное назначение модуса - прецизионно сфокусировать сознание на множестве всех энергий человека и сохранять, воспроизводить определённый строй этих энергий, требуемый для духовного восхождения. Практически все компоненты модуса трезвения и все протекающие в нём процессы имеют прямые соответствия в модусе интенциональности феноменологического сознания. Основные вехи этого соответствия-изоморфизма двух модусов установлены в книге «К феноменологии аскезы», но полная его дескрипция - особая и масштабная проблема, решение которой остаётся будущему.

Наряду с данным соответствием, сопоставление феноменологического и исихастского сознаний должно учитывать и их фундаментальное различие, вызванное мистической природой последнего. Строение исихастского сознания не может исчерпываться сферой трезвения, поскольку исихастская практика, в отличие от интенционального акта, - предельная практика, процесс, восходящий к границе горизонта сознания и опыта. Согласно внутреннему органону исихастского опыта, на центральных этапах этого восходящего процесса, сознание имеет своим ядром прочное сочетание двух базисных элементов, внимания и молитвы. При этом, «внимание» здесь понимается обобщённо, как модус трезвения, «молитва» же имеет специальную форму так наз. «непрестанной молитвы». Из этих элементов, второй - главный, именно им обеспечивается восходящий характер процесса, его продвижение к пределам опыта; тогда как первый - служебный, дело его - создать «пространство молитвы» и его охранять от любых вторжений, помех. В свете этой картины, наше сопоставление может стать полным. В диаде «внимание + молитва» (что то же, «модус трезвения + молитва»), образующей основу исихастского сознания, второй, главный элемент принадлежит не феноменологическому, не интенциональному сознанию (хотя феноменологическое сознание и может ставить задачу его дескрипции, по приводившимся словам Шпета).

Однако же первый элемент, играющий в исихастском органоне огромную роль, практически идентичен интенциональному сознанию. А кроме того, и полная картина malgré tout тоже сохраняет известное соответствие с феноменологией: ибо интенциональное сознание и интенциональный акт тоже, если угодно, служебны - они служат постижению интенционального предмета, который есть, вообще говоря, некая внешняя данность, отнюдь не творимая самим сознанием.

Афонский исихазм: Фаворский Свет и ноэзис. Высшее состояние (телос), к которому направляется исихастская практика, носит название обожение (theosis) и означает актуальную онтологическую трансформацию человеческого существа, его претворение в иной образ бытия, представляемое как совершённое соединение всех энергий человека с энергией, принадлежащей этому иному образу бытия. Предполагается, однако, что в пределах человеческого существования возможны лишь начатки этого бытийного претворения, подступы к нему. Как фиксирует внутренний органон, высшие ступени исихастского опыта (бывшие в центре внимания зрелого поздневизантийского исихазма, с главным очагом на Святой Горе Афон) актуально достигают таких начатков. Здесь опыт духовной практики - уже специфически мистический опыт, в котором начинают меняться фундаментальные предикаты способа существования человека.

По согласным свидетельствам всех духовных традиций, в первую очередь, радикальным изменениям подвергаются восприятия, перцептивные модальности: у человека формируются новые перцепции, которые в исихазме называются «умными чувствами». Как формирование этих перцепций, так и другие происходящие изменения носят характер глобальной трансформации человеческого существа к новому, холистическому устроению, в котором снимаются, преодолеваются разделения 


\section{Философия и культура 5(101) • 2016}

и различия между уровнями организации человека: всё человеческое существо становится единым целым, все энергии которого составляют единство, соединяющееся с энергией иного онтологического горизонта (действием этой энергии и осуществляется онтологическая трансформация). Холистическую организацию обретает и сознание. Структуры «внимания» и «молитвы», бывшие относительно раздельными, сближаются и срастаются воедино, пространство сознания целиком превращается в «пространство молитвы» - и, следовательно, присутствие интенционального сознания в исихастской практике утрачивается. В отличие от начальных ступеней практики (которые осваивал ранний исихазм), в отличие от центральной стадии (на которой концентрировался исихазм синайский), высшие ступени практики, которыми занят афонский исихазм эпохи Исихастского возрождения, не имеют близости к феноменологическому сознанию.

Но этот негативный вывод ещё не исчерпывает тему «Исихазм и феноменология». Именно на своих высших ступенях исихастское сознание и опыт становятся мистическими par excellence становятся такими сознанием и опытом, анализ которых Густав Шпет назвал «интереснейшей философской проблемой». Как мы покажем сейчас, в рамках феноменологии возможно всё же отыскать путь к пониманию подобного опыта.

Сознание на высших ступенях духовной практики - чрезвычайно экзотический феномен, к которому проблематично уже само применение термина «сознание». На этих ступенях человек начинает трансформироваться в «тело без органов», функции и активности которого более принадлежат всему целому, нежели его отдельным частям. Однако, по самому определению практики, также и на этих ступенях главное содержание его активности остается тем же: человек актуализует свою устремлённость к мета-антропологическому Телосу практики, энергийному претворению в иной образ бытия. На подступах к Телосу энергии человека уже собраны воедино и встреча энергий разного бытийного статуса достигнута; завершающая же задача заключается в осуществлении всецелой направленности человеческих энергий на инобытийную энергию. Предполагается, таким образом, что холистический ансамбль всех энергий человека, рождающийся в практике на базе сознания, сохраняет ключевой предикат сознания - способность направленности, нацеленности на предмет, т.е. не что иное как интенциональность. Но теперь это уже не предикат сознания, а предикат трансформированной, холистической антропологической реальности: новая, холистическая интенциональность.
Так открывается возможность интерпретировать высшие ступени исихастской практики также на основе феноменологической (интенциональной) парадигмы. Возможность состоит в обобщении этой парадигмы. Примем, по определению, что способность направленности на предмет, присущая холистической антропологической реальности, формирующейся на подступах к мета-антропологическому Телосу, есть обобщённая форма интенциональности - холистическая интенциональность. (Заметим, что с равным правом эта способность может рассматриваться и как обобщённая форма исихастского трезвения, «холистическое трезвение»; а поскольку интенциональная нацеленность на предмет есть активность интеллектуального (у)зрения, то эта же способность может рассматриваться ещё и как «холистическое зрение». Здесь проявляется фундаментальное родство когнитивных парадигм, принадлежащих трём разным культурам: новоевропейской феноменологической парадигмы интенциональности - византийской исихастской парадигмы трезвения - древнегреческой парадигмы умного зрения.) Тогда назначение и содержание высших ступеней исихастского опыта может трактоваться как «холистический интенциональный акт», в котором интенциональным предметом служит энергия иного образа бытия (подчеркнём: мета-эмпирический, инобытийный «предмет»! - что говорит о радикальности и, в известной мере, дискуссионности делаемого обобщения).

Данный вывод может быть уточнён: как нетрудно увидеть, эти высшие ступени правильней связывать не с интенциональным актом как таковым, но с его заключительной, ноэтической фазой. Исихастское сознание строго телеологично, и хотя каждая ступень исихастской Лествицы имеет своё назначение, однако носителем всей полноты смысла духовного процесса предполагается исключительно Телос, «конец-смысл». Поэтому на финальных ступенях практики, подводящих к Телосу, соединяются и суммируются все продуцируемые в практике смысловые содержания, совершается проницание всей суммы опыта финальным смыслом - что передаётся феноменологическим понятием Sinngebung и отвечает фазе ноэзиса. И опять-таки, с учётом того, что на этих ступенях совершается холистическое претворение антропологической реальности, здесь также следует говорить лишь о «холистическом ноэзисе». Как известно, в исихазме высшие ступени опыта уже не причисляются к «практике» (praxis) и носят особое название «феории», или же «созерцания». В этих терминах, вывод наш означает, что исихастская 
«феория» может интерпретироваться как обобщённая, холистическая форма ноэзиса.

Итак, в аспекте сопоставления с феноменологической парадигмой, и в терминах этой парадигмы, афонский и византийский исихазм XIII-XIV вв. был преимущественно сосредоточен на ноэтической (а, следовательно, и ноэматической) фазе опыта. При этом в опыте высших ступеней исихастской практики (или, более точно, феории) надо усматривать не обычный, а обобщённый, холистический ноэзис, осуществляемый не сознанием (или не только сознанием), а холистически трансформирующейся антропологической реальностью.

Общий смысл нашего рассмотрения вполне очевиден. Анализ, даже не самый тщательный, обнаруживает обширные и глубокие соответствия, совпадения между феноменологической парадигмой опыта и структурами опыта в духовной практике - ближайшим образом, в исихазме. Проделанный анализ был крайне далёк от полноты, и выявленный репертуар сближений было бы нетрудно дополнить. Но самое примечательное и важное в другом. Как мы убеждаемся, феноменологический (интенциональный) строй - естественный строй если и не религиозного сознания вообще, то, по крайней мере, квинтэссенциально и аутентично религиозного сознания - сознания в духовной практике. Благодаря этому феноменология выступает как философский дискурс, наиболее адекватный для понимающей дескрипции духовной практики. Хотя исихастское сознание и феноменологическое сознание работают в разных опытных горизонтах, однако за счёт общих принципов примата опыта и строгой проработки опыта, за счёт общего внимания к технике контроля и технике фиксации содержаний сознания, они приобретают и комплекс общих трансцендентальных структур.

Однако не следует и абсолютизировать этот альянс. Напомним, что в начале статьи мы выделили в теме «Исихазм и философия» три основных топоса, затем рассмотрев лишь один из них. Два топоса, оставленных в стороне, - топос энергии и топос антропологического размыкания - отнюдь не имеют исключительной опоры на феноменологию. И в целом, феномен духовной практики столь сложен и многомерен, что его всесторонняя интерпретация заведомо нуждается в привлечении и других философских арсеналов.

Вывод более общий состоит в пробивающем себе дорогу единстве человеческого опыта. Как мы убедились, пограничный, предельный опыт, где культивируется превосхождение самой человеческой природы, отнюдь не должен рассматриваться как некий маргинальный островок опыта, как нечто эксцентрическое и оторванное от всего. Вопреки застарелым оппозициям и барьерам, он оказывается не на другом полюсе от современного и строгого научного опыта, а в тесном родстве с ним. Многообразие человеческого опыта пронизано органическими связями, идущими поверх барьеров и сквозь перегородки, выстроенные классическим разумом, и сегодня оно должно мыслиться и структурироваться по-новому.

\section{Список литературы:}

1. Шпет Г.Г. Мудрость или разум? // Мысль и слово. I. М., 1917. С. 46, 48.

2. Хоружий С.С. Фонарь Диогена. Критическая ретроспектива европейской антропологии. М., 2010. С. 426-473, 487-491.

3. Шпет Г.Г. Письмо к Э. Гуссерлю от 14.XII.1913 // Логос. 1996. № 7. С. 125.

4. Преп. Иоанн Лествичник. Лествица 2,1; 27,46. Сергиев Посад, 1894. С. 28, 238.

\section{References (transliterated):}

1. Shpet G.G. Mudrost' ili razum? // Mysl' i slovo. I. M., 1917. S. 46, 48.

2. Khoruzhii S.S. Fonar' Diogena. Kriticheskaya retrospektiva evropeiskoi antropologii. M., 2010. S. 426-473, 487-491.

3. Shpet G.G. Pis'mo k E. Gusserlyu ot 14.XII.1913 // Logos. 1996. № 7. S. 125.

4. Prep. Ioann Lestvichnik. Lestvitsa 2,1; 27,46. Sergiev Posad, 1894. S. $28,238$. 